\title{
MANAGEMENT OF THE PRODUCTION OF SOLID WASTES OF THE COMANDANTE FERRAZ BRAZILIAN ANTARCTIC BASE
}

http://dx.doi.org/10.4322/apa.2014.053

\author{
Anderson Buss Woelffel ${ }^{1, *}$, Cristina Engel de Alvarez ${ }^{1}$
}

${ }^{1}$ Universidade Federal do Espírito Santos - UFES, Vitória, ES, Brazil

*e-mail: andersonbwarquiteto@gmail.com

Abstract: Since 2001, specific studies on the subject of solid wastes produced at the Comandante Ferraz Brazilian Antarctic Base (EACF) have been carried out in order to characterise, quantify and identify the overall production of solid wastes in several activities performed in that Antarctic station. In 2006 a new spreadsheet to control the wastes was adopted in order to optimize the monitoring task, from the initial collection to final storage. Thus, this study is aimed at assessing the annual production of solid wastes, specifically from January 2009 to March 2010, and researching significant potential changes in the waste quantities after application of the new spreadsheet, based on the values of the production from 2001 to 2008 (historic series). Methodologically, the past results of production of wastes of the EACF and the data of current situation supplied by SECIRM were analyzed. From the results, a general increase of the solid wastes documented from 2006 was noted, reflecting improvement in procedures in the identification and quantification of waste generated at EACF. This increase is concurrent to two factors affecting the final production of waste: the early studies of the EACF Revitalization Program and the increase of the number of users at the station.

Keywords: solid residues, waste, Antarctica, environmental monitoring

\section{Introduction}

Since the establishment of the Comandante Ferraz Brazilian Antarctic Base (Lat. $=62^{\circ} 05^{\prime} \mathrm{S}$ and Long. $=58^{\circ} 24^{\prime} \mathrm{W}$ ), mark of Brazilian presence in Antarctica, the concern with the destination of the solid wastes produced through the undertaking of a number of local activities has been constant in the scope of the Brazilian Antarctic Program (PROANTAR, acronym in Portuguese) and have encouraged initiatives in order to cause minimal environmental impact as a consequence of Brazilian occupancy on that continent (Alvarez et al., 2006).

With the advent of the Madrid Protocol (1991), which in its Appendix 3 deals with the issue of solid waste by advocating that all garbage should be removed from area of the Antarctic Treaty, the practices previously developed were renewed. Nevertheless, little was known about the production quantities and some more specific waste categories were clustered into related categories, which made their correct management difficult.

Since 2001, with the goal to fill that information gap, specific studies on the issue of solid wastes at the Comandante Ferraz Brazilian Antarctic Base have been undertaken, aiming mainly to characterise, quantify and identify the general production of wastes related to the several activities developed at the EACF. In 2006/2007, further studies focused on the waste generated by the activities of production and consumption of food (Alvarez et al., 2007a); and in the summer 2007/2008, all the waste management process was investigated, from the initial collection to final storage.

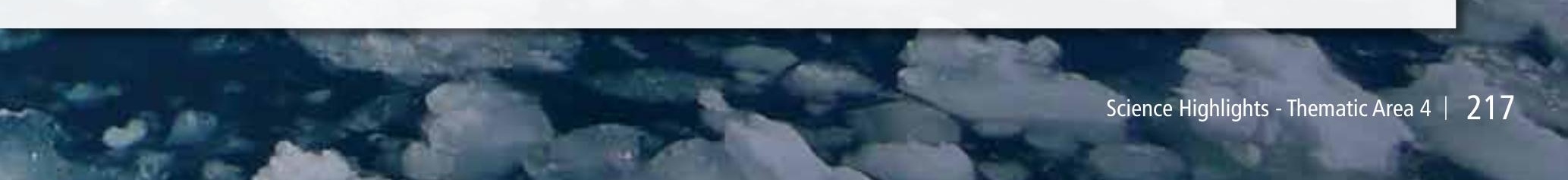


In 2006, as a reflex of a change in the systematic selection and measurement, a new spreadsheet of control of the production of solid wastes in the EACF was adopted, aiming at optimizing the management task, as a result seeking to know and quantify better the waste for directing initiatives of specific treatment and final destination.

The spreadsheet in question discriminated new categories and subdivided other general categories into specific waste amounts. This innovation was quite satisfactory since to perform correct waste management it is necessary to first diagnose carefully its production, sectorization and quantification (Maroun, 2006).

\section{Aims}

The primary aim of this research is to evaluate the production of solid waste generated in the EACF, based on the data obtained from the Reports of Waste Generated in EACF, provided by SECIRM (Secretariat of the Interministerial Commission for Resources of the Sea), specifically between January 2009 and March 2010. It is also aimed to study significant potential changes in the waste quantities after application of a new spreadsheet, based on the recorded values of the production from 2001 to 2008 (historical series).

The secondary aim is to proceed the studies integrating a wider technological research project which has been developed making use of the scope of the Brazilian Antarctic Program (PROANTAR), whose general aim is to develop solutions to optimize the systems operating in EACF and the environmental efficiency of the Brazilian buildings on Antarctica as a whole, also considering the reproducibility of methodology and the solutions proposed in similar situations and the pertinence of this subject for the country's economy.

\section{Methodology}

To develop this work the past results of the production of wastes in EACF and the data of the current situation provided by SECIRM were analyzed. The current data was treated according to classification proposed by the new spreadsheet and quantitative graphs for the time period covered in each category were designed. Then, the data was reassembled and the overall results were divided between productions in summer and in winter for addition to the historical series.

\section{Results}

The spreadsheet adopted from 2006 contains not only information related to solid waste itself but also data of the fuel consumption, separated by category, in addition to a section that predicts the recording of sewage and household waste. However, the absence of hydrometers in the related piping at the EACF impedes the measurement of effluent. Moreover, the spreadsheet also covers the production of chemical liquid, fuels, hospital, scientific research waste, in addition to waste from constructions and maintenance of buildings. Another aspect to be considered when analyzing the spreadsheet is that it informs, in general lines, the control method for each category.

Initially, the data from gross production of waste was compared and their treated results were inserted in the historical series from 2001 to 2008 (Figure 1). the overall increase of the documented production of solid waste from 2006 was noted, including year of adoption of the new spreadsheet, in comparison with the former years, i.e., from 2001 to 2005 , reflecting improvement in the procedures of identification and quantification of the waste generated in EACF. This increase is concomitant to two factors affecting the final production of waste: the initial studies of the EACF

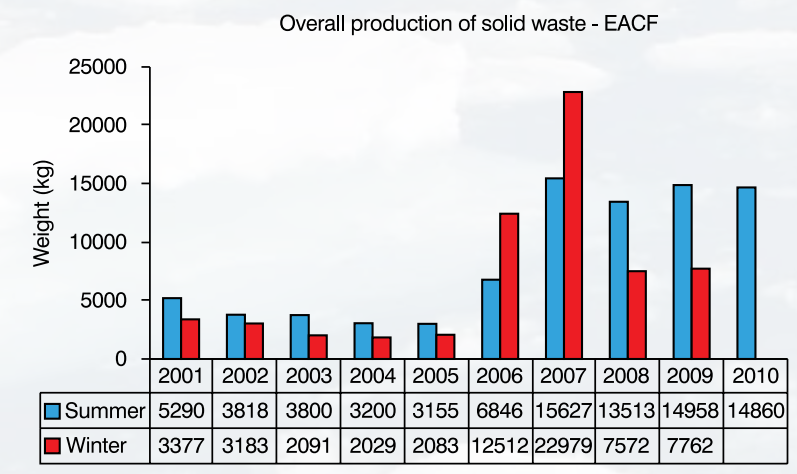

Figure 1. Generation of solid waste in the EACF: comparison between summer and winter. The increased amounts of waste noted in 2007 reflect the period of intensive works to revitalize the Base. 


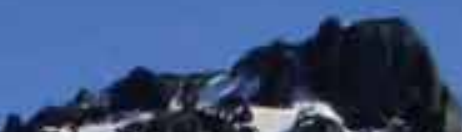

Revitalization Program (Alvarez et al., 2007b) and the extension of the number of users of that station.

Another aspect to be considered when interpreting the Graph in question concerns the initial tendency for stabilization of the total production of waste from 2008, which should be investigated in future measurements.

The waste materials contaminated with paint and oil/ grease reached the peak of $904 \mathrm{~kg}$ in October, which is well above the mean of $145.81 \mathrm{~kg}$ among the considered months (Figure 2). It should be observed that in the period the cleaning of fuel tanks of EACF with consequent extension of that waste class occurred.

Furthermore in October, the scrap quantity reached the value of $547 \mathrm{~kg}$, above the mean of $191.2 \mathrm{~kg}$ (Figure 3), corresponding to the period in which were carried out the preparations of the waste produced during the winter for embarkation.

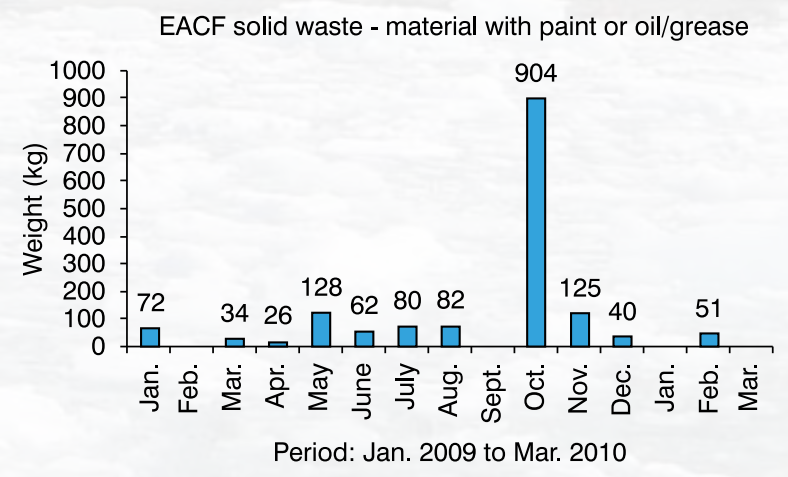

Figure 2. Production of waste materials contaminated with paint or oil/ grease in the EACF, with increased quantity in October 2009.

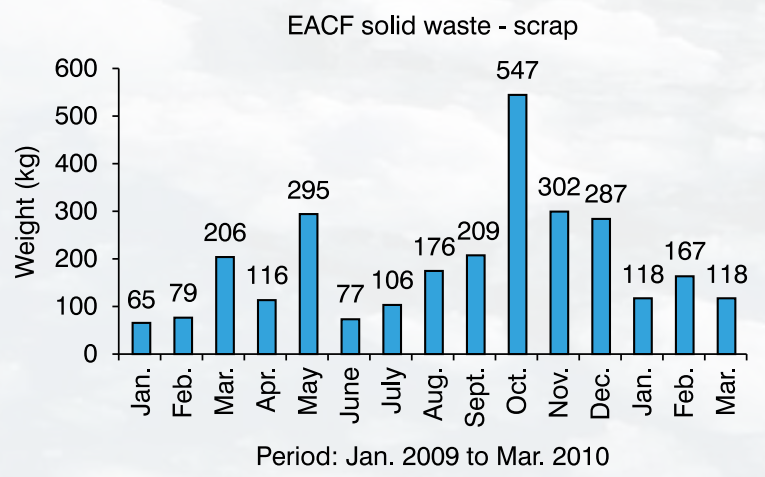

Figure 3. Production of waste scrap in the EACF, with increased quantity in October 2009
The quantity of organic waste measured in December was $1,601 \mathrm{~kg}$, above the mean of $925 \mathrm{~kg}$ of the other months in the summer of 2009/2010 (Figure 4). It was noted that with the arrangement of provisions coming with the ship in early summer a routine evaluation of existing stock is established, particularly concerning the conditions of stored material consumption. Thus, in that period were discarded $892 \mathrm{~kg}$ of refrigerated provisions in addition to $427 \mathrm{~kg}$ of dry provisions classified as not suitable for consumption.

Concerning the paper waste, an increase of production in March 2009 was found, above the mean of $159.26 \mathrm{~kg}$ (Figure 5). This may be explained by activities of organization of material and discarding of unnecessary packages during the winter, considering the concentration of loading for embarkation for return to Brazil.

With respect to the waste related to construction and maintenance activities, there is special attention on the

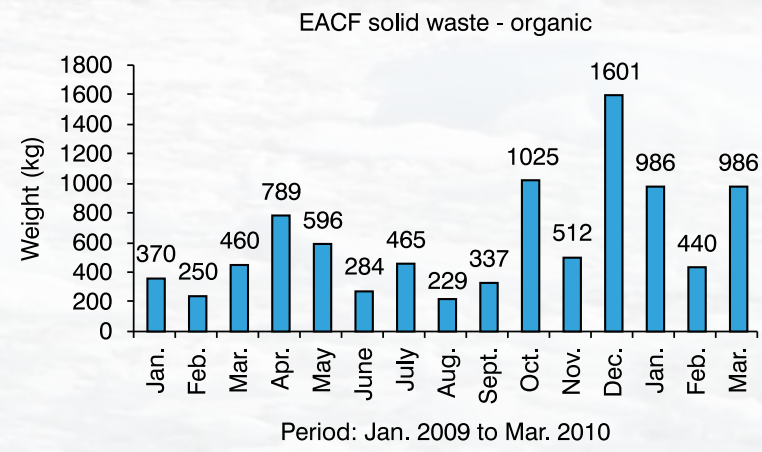

Figure 4. Production of organic waste in the EACF, with increased amount in December 2009

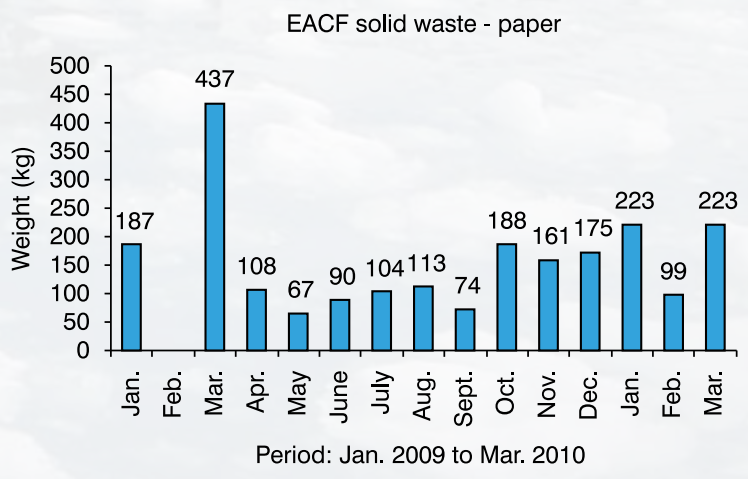

Figure 5. Production of paper waste in the EACF, with increased amount in March 2009 
production of polyurethane and polystyrene foam waste, as well as the production of PVC waste, also comprising in this category other plastics.

In March 2009, it was found that the EACF produced significant quantities of polyurethane and polystyrene foam $(235 \mathrm{~kg})$, most likely due to works of repair in the location called Spares Bunker, whose isolating material was practically completely replaced.

Concerning the increased production of PVC and other plastics in December 2009 (286 kg), this fact very likely was related with the discarding of 19 damaged "marfinites", according to a specific report of the month. The term "marfinite" refers to a box with a standard size, made from rigid PVC and used by PROANTAR to transport and temporarily store materials.

\section{Conclusions}

It is highlighted that a detailed categorization of the production of waste allows effective knowledge of the material used in the EACF, either for routine or eventual activities. This in turn allows the study of alternatives to reduce the production of waste, its final destination and even the feasibility of its replacement for other materials whose performance is more efficient from a logistic and environmental standpoint.

It is worth mentioning that relevant advances were obtained, especially for the rigor and reliability of the data recorded in the worksheet, allowing for an appropriate diagnosis of the production of solid waste. The acquisition of a new incinerator is also noteworthy, characterised by greater ability to burn and reduce the release of pollutants into the atmosphere, furthermore the evaluation of the feasibility of reusing the heat generated during the incineration of organic materials for energy co-generation in the EACF is under study. However, still due to the lack of adequate studies of the system for measuring and evaluating wastewater, investments both in measurement equipment and in training personnel to perform the activities are needed.

Although desirable for understanding the problem of waste on Antarctic soil and for the proposal of management alternatives, comparing data of waste production of EACF with data from other Antarctic stations cannot be undertaken directly, especially in light of the following aspects: 1) difficulty of obtaining data by the official coordinators of activities in Antarctica, mainly for countries that are out of the RAPAL(Meeting of Latin-American Antarctic Manager Programs) system; 2) measurements made by other bases or stations using different methodology of that adopted by the Brazilian station makes it hard or impossible to obtain a desirable result correlation; and 3) different user habits, related with the culture of their country of origin, interfering, especially, in the amount of waste generated.

The continuity in measurements and data processing must be a priority due to its primary importance for the development of appropriate solutions to the problem of solid waste in Antarctica and also to the possible interrelation with other areas of knowledge. Therefore, the study on the co-generation of energy deserves to be mentioned, which would take into account the solid waste combustion, an important source to be exploited.

\section{Acknowledgements}

We thank the FAPES (Foundation for Support of Science and Technology of the Espírito Santo), the CNPq (National Council for Scientific and Technological Development), and the SECIRM (Secretariat of the Interministerial Commission for Resources of the Sea).

We also thank National Institute of Science and Technology for Environmental Research in Antarctica (CNPq, process $\mathrm{n}^{\circ} 574018 / 2008-5$ and FAPERJ, process $n^{\circ}$ E-16/170,023/2008). 


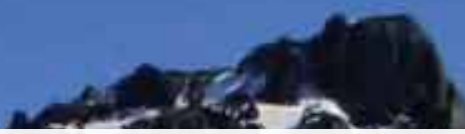

\section{References}

Alvarez, C.E.; Woelffel, A.B.; Cruz, D.O. \& Marchi, L.B. (2007a). Evaluación de la producción de residuos sólidos resultantes de las actividades de elaboración y consumo de alimentos en la Estación Antártica Comandante Ferraz (BRASIL). Documento de Información de La XVIII RAPAL - Reunión Anual de Administradores Antárticos Latinoamericanos, Brasília. p. 1-8.

Alvarez, C.E. de, Casagrande, B. \& Soares, G.R. (2007b). Resultados alcançados com a implementação do Plano Diretor da Estação Antártica Comandante Ferraz (EACF). Anais do IV Encontro Nacional e II Encontro Latino-Americano Sobre Edificações e Comunidades Sustentáveis, Campo Grande. p.1297 - 1306.

Alvarez, C.E. de; Marchi, L.B.; Cruz, D.O.; Soares, G.R. \& Paneto, G.G. (2006). Diagnóstico Preliminar dos resíduos gerados na EACF - Estação Antártica Comandante Ferraz, Brasil. Documento de Información de La XVII Reunión Anual de Administradores Antárticos Latinoamericanos, Punta Arenas.

Maroun, C.; Firjan, S. (2006). Manual de Gerenciamento de Resíduos: Guia de procedimento passo a passo. Rio de Janeiro: GMA.

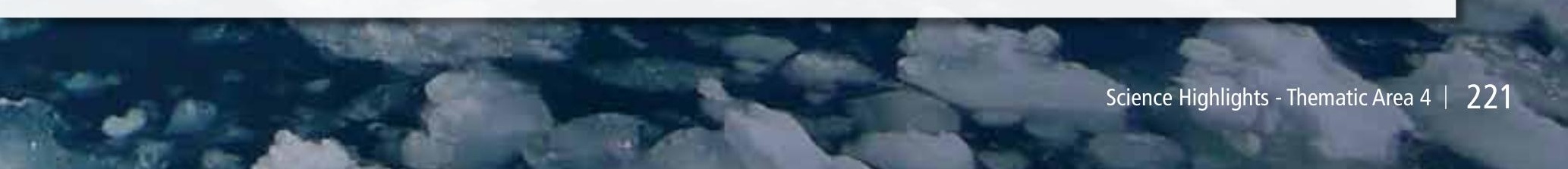

